\title{
Present-day relative displacements between the Jeju Island and the Korean peninsula as seen from GPS observations
}

\author{
Ahmed M. Hamdy ${ }^{1,2}$, Pil-Ho Park ${ }^{1}$, Hyung-Chul Lim ${ }^{1}$, and Kwan-Dong Park ${ }^{3}$ \\ ${ }^{1}$ Korea Astronomy Observatory, 61-1, Hwaam-dong, Yuseong-gu, Daejeon 305-348, South Korea \\ ${ }^{2}$ Geodynamic Department, National Research Institute of Astronomy and Geophysics, Helwan, Cairo, Egypt \\ ${ }^{3}$ College of Forest Science, Kookmin University, 861-1 Jungnung-dong Sungbuk-gu, Seoul 136-702, Korea
}

(Received December 12, 2003; Revised August 6, 2004; Accepted August 6, 2004)

\begin{abstract}
We use three years data from six permanent GPS stations, in the Korean peninsula and Jeju Island, to examine the relative displacement between Jeju Island and the Korean peninsula and whether the Jeju Island lies on the Amurian Plate or not. Out of these stations, three sites, considered to be on the stable interior of the Amurian Plate (the Korean peninsula), showed relative velocities less than $1.3 \mathrm{~mm} / \mathrm{yr}$. On the other hand, the maximum velocity of the Jeju Island stations was $2.1 \mathrm{~mm} / \mathrm{yr}$ with respect to DAEJ station, and the average relative velocity between the island stations and those in the main land are less than $1.7 \mathrm{~mm} / \mathrm{yr}$. By comparing these results with other velocities within the Amurian Plate, we found that the observed velocities are intra-plate. Our results are supported by geological evidences and seismological records, which claimed that the Korean peninsula and the Jeju Island are on the same plate. Hence, the Amurian Plate boundary line is considered to lie somewhere to the south of Jeju Island.
\end{abstract}

Key words: GPS, Korean peninsula, Jeju Island, Amurian Plate.

\section{Introduction}

Two Major factors are controlling the tectonics of eastern Asia (Fig. 1): 1) subduction of oceanic plates (the Pacific Plate and the Philippine Sea Plate) and 2) the collision of the Indian Plate with the Eurasia Plate resulting in the eastward expulsion of relatively small continental plates (Molnar and Tapponnier, 1975). The regional tectonics and seismicity suggest the existence of the Amurian Plate embracing northeast China, the Korean peninsula, the East Sea (Japan Sea), and the southeastern part of Russia (Zonenshain and Savostion, 1981). Moreover, they suggested that the Southern boundary of the Amurain Plate runs from the southern end of the Baikal Lake, along the eastern tip of the Bogdo fault and the northern margin of Shanxi Graben, to the central part of Bohai Sea until it connects with the southern tip of Nankai Trough. In addition, Wei and Seno (1998) traced out the Amurain Plate boundary line (line A-Fig. 1) as it was suggested by Zonenshain and Savostin (1981), but they show that the Jeju Island is lying out of the Amurain Plate (see Wei and Seno, 1998, figures 2 and 4). On the other hand Kato (2003), studied the tectonics of the eastern Asia and the western Pacific region using GPS observations, he claimed that the southern boundary of the Amurain Plate (line BFig. 1) are lying somewhere within the Korean Peninsula to the south of Daejeon (see figures 2 and 5 of his study).

The Jeju Island is a typical shield volcano located on the continental margin at the southern end of the Korean peninsula. The island was formed by alkaline basaltic magma

Copy right (C) The Society of Geomagnetism and Earth, Planetary and Space Sciences (SGEPSS); The Seismological Society of Japan; The Volcanological Society of Japan; The Geodetic Society of Japan; The Japanese Society for Planetary Sciences; TERRAPUB. similar to normal continental and oceanic alkaline basalt (Chough et al., 2000). The alkaline volcanic rocks of the Jeju Island erupted between Pleistocene (1.2 Ma) and Holocene (AD 1570) (Won et al., 1986; Yun et al., 1987; Min et al., 1988). The combined geochemical and Nd-Sr isotopical characteristics and radiometric ages of the granitic rocks from Jeju Island indicate that the basement of the island is correlated with the Okchan zone (Fig. 1) (Kim et al., 2002), and they conclude that the Okchan zone (in the Korean peninsula) is continuously extended to the Jeju Island.

Analysis of space geodetic data such as Global Positioning System (GPS) have demonstrated that movements of major plates in a geodetic time window (a few years) are consistent with those averaged over a few millions of years (Heki, 1996; Larson et al., 1997). These data are useful especially for crustal movement and plate tectonic studies, since it provides velocities (i.e., both directions and rates) at necessary points on the plate in question and it dose not require exact knowledge of plate boundaries. Moreover, these data will contribute to defining the plate boundary when the points are densely distributed (Heki et al., 1999).

Heki et al. (1999) investigated the relative movement between the Amurian Plate and the Eurasian Plate by using GPS velocity data from 15 stations distributed in Korea, Russia, China and Japan. Out of these stations, three sites (DAEJ and SUWN in Korea, and VLAD in Russia) were selected to be on the stable interior of the Amurian Plate. Their results indicated that the Amurian Plate shows an eastward velocity $9-10 \mathrm{~mm} / \mathrm{yr}$ with respect to the Eurasian Plate, while the intra-plate velocities are within $1 \mathrm{~mm} / \mathrm{yr}$.

The precise surveying using GPS in South Korea started with the establishment of the first permanent GPS station 


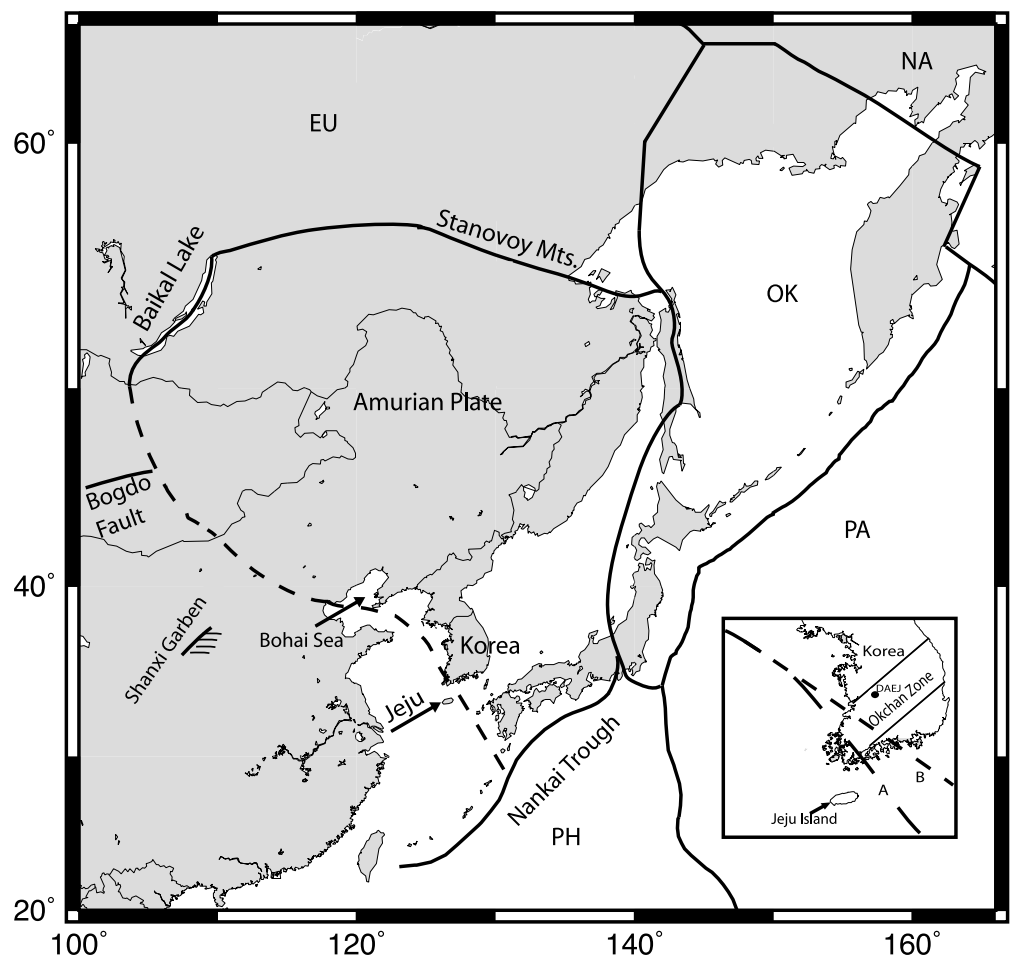

Fig. 1. Plate tectonic framework of the East Asia. $\mathrm{EU}=$ Eurasian Plate, $\mathrm{NA}=$ North American $\mathrm{Plate}, \mathrm{OK}=\mathrm{Okhostk} \mathrm{Plate}, \mathrm{PA}=\mathrm{Pacific} \mathrm{Plate}, \mathrm{PH}=\mathrm{Philippine}$ Sea Plate and DAEJ=Daejeon. The dashed lines are the southern boundary of AM-EU. All the boundaries are after Wei and Seno (1998). A=boundary after Wei and Seno (1998). B=boundary after Kato (2003).

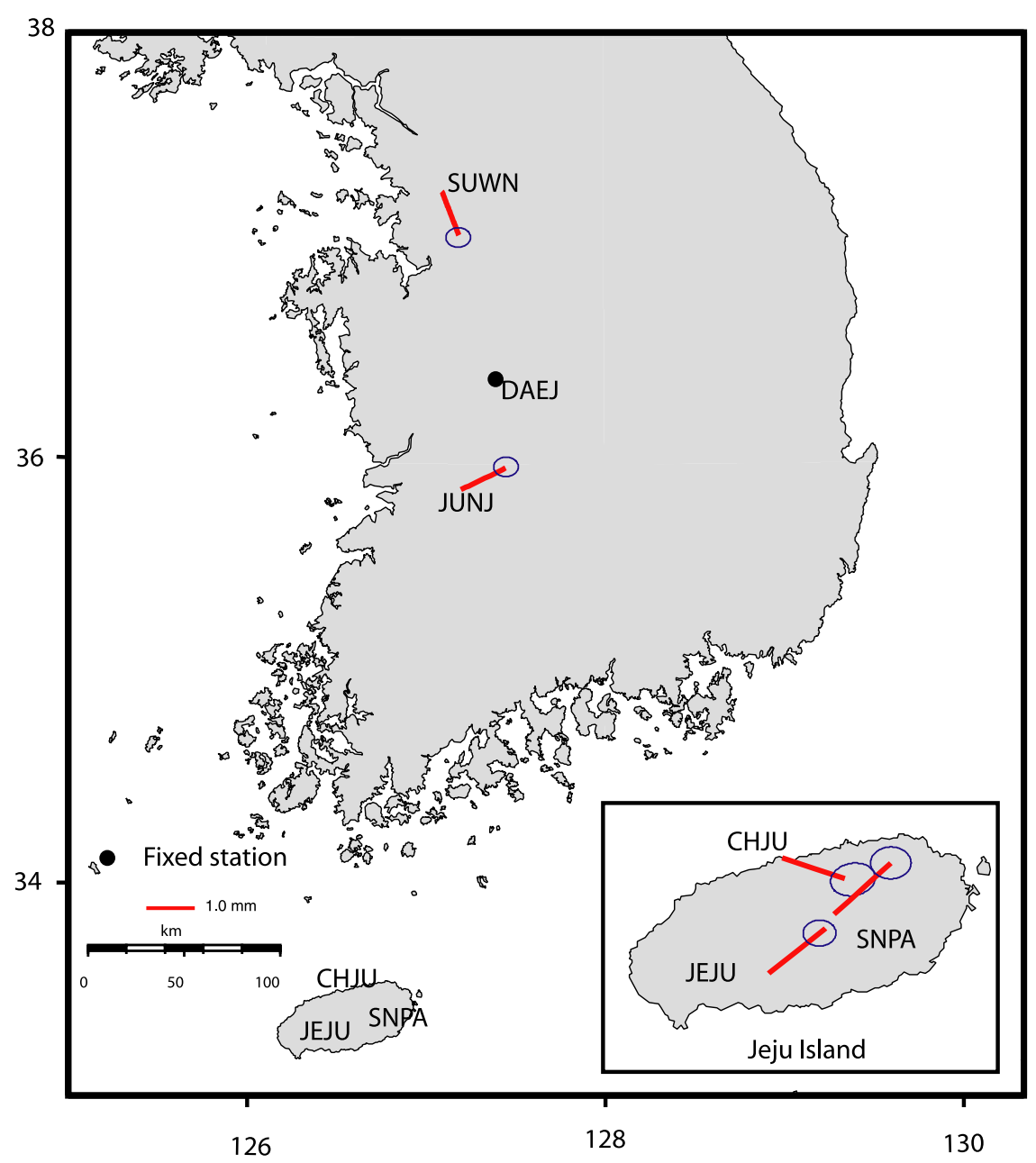

Fig. 2. Velocities of GPS stations with respect to DAEJ and their error ellipses with a confidence limit of $95 \%$. 

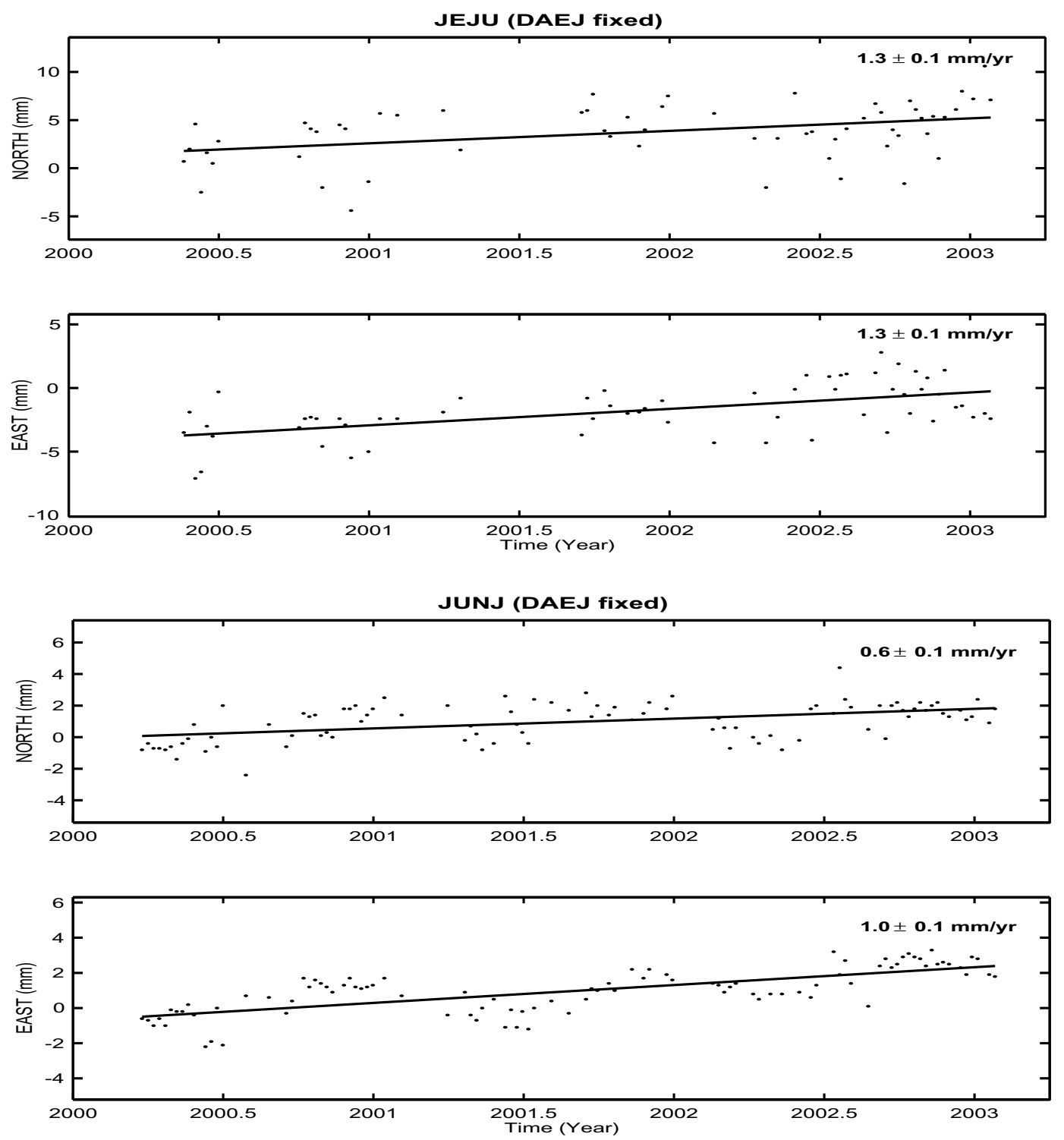

Fig. 3. Time series of horizontal coordinates for two selected sites with respect to DAEJ station. Solid lines are the best fit lines for temporal changes of the east and north component.

in 1994, and more than 70 permanent GPS stations operate in South Korea now (Park et al., 2001). In our paper, we investigate the relative movement between the Jeju Island and the Korean peninsula, and examine whether the Jeju Island resides on the Amurian Plate or not.

\section{Data Processing}

We analyzed three years data (April 2000 to March 2003) from six GPS sites, constructed on geologically stable marks (pillars), in the Korean peninsula and Jeju Island; two of them (DAEJ and SUWN) are International GPS Service (IGS) stations (Fig. 2). All these stations have dualfrequency receivers Trimbel 4000SSi with two different antenna types (Table 1). Bernese software version 4.2 was used in data processing; the IGS final orbits, satellite clock offsets, and IGS Earth orientation parameters were used in the data processing. The tropospheric delay was estimated by using the GPSEST program and the quasi-ionosphere free (QIF) strategy was employed for the ambiguity resolution (Beutler et al., 2001). The ADDNEQ program of the Bernese software was used to combine all the normal equations; from the daily GPSEST solutions, and then a weekly solution were produced. These normal equations were combined into free solution, where the stations were selected to define the minimum constrained condition in the ADDNEQ program. The free solution has the purpose of outlier detection. After the exclusion of all the outliers, a fixed solution was generated where DAEJ station is considered to be fixed in the ITRF97 reference frame.

Finally, the relative station velocities were estimated and are listed with their RMS errors in Table 1. Examples of the horizontal coordinate's time series are shown in Fig. 3.

\section{Results and Discussion}

The two stations in the stable part of the Amurian Plate, namely SUWN and JUNJ were found to move by 1.3 $\mathrm{mm} / \mathrm{yr}$ and $1.1 \mathrm{~mm} / \mathrm{yr}$, respectively, with respect to DAEJ (Fig. 2). These velocities are similar to the intra-plate veloc- 


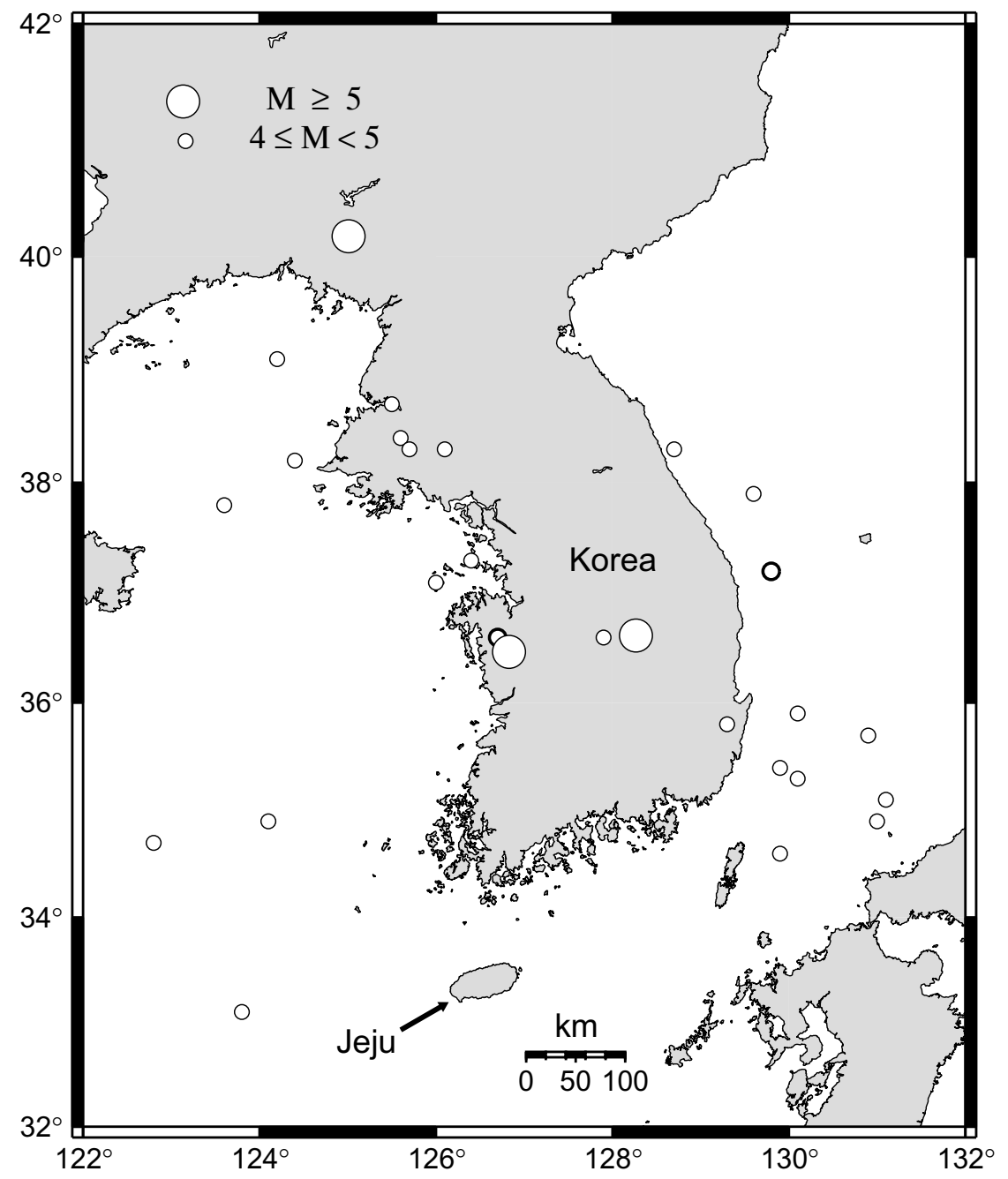

Fig. 4. Epicentral distribution map of the earthquakes in the Korean peninsula from 1978 to 2000 with magnitudes larger than 4 . After Hamdy and Jo (2003).

Table 1. Site velocities relative to DAEJ and their standard errors. +: the station uses TRM33429.00 Antennae, *: the station uses TRM29659.00 Antennae.

\begin{tabular}{|c|c|c|c|c|c|c|}
\hline \multicolumn{3}{|c|}{ Station } & \multicolumn{2}{|c|}{ Velocity, $\mathrm{mm} / \mathrm{yr}$} & \multicolumn{2}{|c|}{ Error, mm/yr } \\
\hline Name & Latitude & Longitude & North & East & North & East \\
\hline & $\mathrm{E}$ & $\mathrm{N}$ & & & & \\
\hline $\mathrm{CHJU}^{+}$ & 33.51 & 126.53 & -0.7 & 1.4 & 0.09 & 0.11 \\
\hline DAEJ* & 36.38 & 127.36 & 0.0 & 0.0 & - & - \\
\hline JEJU* & 33.29 & 126.46 & 1.3 & 1.2 & 0.11 & 0.11 \\
\hline JUNJ* & 35.80 & 127.14 & 0.6 & 0.9 & 0.05 & 0.05 \\
\hline SNPA* & 33.38 & 126.62 & 1.5 & 1.5 & 0.13 & 0.13 \\
\hline SUWN* & 37.28 & 127.05 & -1.3 & 0.3 & 0.05 & 0.05 \\
\hline
\end{tabular}

ities shown in Heki et al. (1999). The observed velocities of the three stations in Jeju Island, CHJU, SNPA and JEJU, with respect to DAEJ, were $1.6 \mathrm{~mm} / \mathrm{yr}, 2.1 \mathrm{~mm} / \mathrm{yr}$ and 1.7 $\mathrm{mm} / \mathrm{yr}$, respectively. CHJU station, which is in the northern part of the Jeju Island, shows slightly different direction, but this irregularity is considered to reflect some local instability. Although the relative velocities between the Jeju Island and the Korean peninsula are greater than those between the stable part of the Amurian Plate $(1 \mathrm{~mm} / \mathrm{yr})$, they were found to be within the measurements error (see Heki et al., 1999, figure 1(a), table 1 and Table 1 of this paper).

The earthquakes are not randomly distributed over the Earth's surface. They tend to be concentrated in narrow zones (belts) and these belts define the boundaries of the plates, while the interiors of the plates themselves are largely free of large earthquakes (Mogi, 1985; Asada, 1982). From 
this viewpoint, we checked out the seismicity in and around the Korean peninsula. The average number of recorded earthquake events is twenty per year since 1978 (KMA, 2002), and these events are generally small earthquakes. The largest recorded earthquake in the Korean peninsula was in 1980 and it has magnitude of 5.3 on the Richter scale (KMA, 2002). Figure 4 depicts the major earthquakes occurred in and around the Korean peninsula with magnitudes larger than or equal to 4.0. These seismological records suggest that there is no seismic activity between the Korean peninsula and Jeju Island. Moreover the geological evidence provides that the Jeju Island basement is similar to that of the Korean peninsula (e.g. Kim et al., 2002).

The present study has not precisely detected the Amurian Plate southern boundary line, but it shows that the boundary lies somewhere to the south of Jeju Island and it denies the boundary lines represented in the past studies (Wei and Seno, 1998; Kato, 2003).

\section{Conclusion}

From the previous discussion we conclude that, (1) The relative velocities between the stations on the stable part of the Amurian Plate are less than $1.7 \mathrm{~mm} / \mathrm{yr}$. (2) This study denies the presence of both boundaries A and B suggesting that the Korean peninsula and the Jeju Island are on one plate (the Amurian Plate).

Future studies are planned to get more precise determination of the southern boundary of the Amurian Plate considering the Ocean bottom topography and seismic velocity in the Yellow Sea.

Acknowledgments. The authors thank the National Geographic Information Institute of Korea and the Ministry of Government Administration and Home Affairs for contributing their data. The critical review of Dr. Manabu Hashimoto and Dr. Teruyuki Kato together with the kind support and advises of Prof. Kosuke Heki improve much the manuscript and point out a promised future research work in Jeju Island. This work was supported by the Korean Ministry of Science and Technology via grant M2031301000103A0213-00410.

\section{References}

Asada, T., Earthquake Prediction Techniques and their Application in Japan, edited by T. Asada, translated by M. Ohnuki, University of Tokyo Press, Tokyo, 1982.
Beutler, G. F., et al., Bernese GPS software Version 4.2, Astronomical institute, University of Bern, 2001.

Chough, S. K., S. T. Kwon, J.-H. Ree, and D. K. Choi, Tectonic and sedimentary evolution of the Korean peninsula: Review and new view, $J$. Earth-Science Reviews, 52, 175-235, 2000.

Hamdy, A. M. and B. Jo, Proposed program for monitoring recent crustal movement in the Korean peninsula, Journal of Korean Geophysical Society, 5, 283-292, 2003.

Heki, K., Horizontal and vertical crustal movement from three-dimensional very long baseline interferometer kinematic reference frame: Implication for the geomagnetic timescale revision, J. Geophys. Res., 101(B2), 31873198, 1996.

Heki, K., S. Miyazaki, H. Takahashi, M. Kasahara, F. Kimata, S. Miura, N. F. Vasilenko, A. Ivashchenko, and K. An, The Amurian Plate motion and current plate kinematics in eastern Asia, J. Geophys. Res., 104(B12), 29147-29155, 1999.

Kato, T., Tectonics of the eastern Asia and the western Pacific as seen by GPS observations, Geosciences Journal, 7(1), 1-8, March 2003.

Kim, K. H., T. Tanaka, K. Suzuki, K. Nagao, and E. Park, Evidences of presence of old continental basement in Cheju volcanic Island, South Korea, revealed by radiometric ages and $\mathrm{Nd}-\mathrm{Sr}$ isotopes of granitic rocks, Geochemical J., 36, 421-441, 2002.

Korean Metrological Administration, Earthquake observation report from 1978-2000, Korean Metrological Administration, Seoul, 2002.

Larson, K. M., J. T. Freymueller, and S. Philipsen, Global plate velocities from the Global Positioning System, J. Geophys. Res., 102(B5), 99619998, 1997.

Min, K. O., O. J. Kim, and S. Yun, Applicability of plate tectonics to the post late Cretaceous igneous activity and mineralzation in the southern part of South Korea (II), J. Geol. Soc. Korea, 24, 11-40, 1988 (in Korean).

Mogi, K., Seismic belts and active periods, in Earthquake prediction, pp. 69-80, Academic Press, INC. Orlando, Florida, 1985.

Molnar, P. and P. Tapponnier, Cenozoic tectonic of Asia: Effects of a continental collision, Science, 189, 419-426, 1975.

Park, P.-H., U. Chwae, Y.-W. Han, and H. Choi, Preliminary GPS results and a possible neotectonic interpretation for South Korea, Earth Planets Space, 53, 937-941, 2001.

Wei, D. and T. Seno, Determination of the Amurian plate motion, in Mantle Dynamics and Plate Interactions in East Asia, Geodynamics Ser., edited by M. F. J. Flower et al., 27, pp. 337-346, AGU Washington, D.C., 1998.

Won, J. K., J. Matsuda, K. Nagao, K. H. Kim, and M. W. Lee, Paleomagnetism and radiometric age of trachytes in Jeju Island, Korea, J. of Korean Inst. Mining Geol., 19, 25-33, 1986 (in Korean with English abstract).

Yun, S. K., D. S. Han, and D. Y. Lee, Quaternary geology in the southern part of Cheju Island, Korean Inst. of Energy and Resources Report, KR86-2-(B)-2, pp. 64, 1987 (in Korean).

Zonenshain, L. P. and L. A. Savostin, Geodynamics of the Baikal rift zone and plate tectonics of Asia, Tectonophysics, 76, 1-45, 1981.

A. M. Hamdy (e-mail: amhamdy_eg@yahoo.com), P.-H. Park (e-mail: phpark@kao.re.kr), H.-C. Lim (e-mail: hclim@kao.re.jp), and K.-D. Park (e-mail: kwondong@yahoo.com) 